\title{
Quality primary health care will drive the realization of universal health coverage
}

\author{
Sagar Dugani MD PhD, Jeremy Veillard PhD, Timothy G. Evans MD PhD
}

— Cite as: CMAJ 2018 April 16;190:E453-4. doi: 10.1503/cmaj.180186

See related article at www.cmaj.ca/lookup/doi/10.1503/cmaj.170784

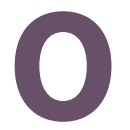

ne notable objective among the 2015 Sustainable Development Goals, an ambitious list of 169 targets to transform global development by 2030 (www.un.org/ sustainabledevelopment/), is the achievement of universal health coverage, which envisions that people everywhere should have access to quality health services without experiencing financial hardship. Achieving universal health coverage is proving difficult, however. At least half of the world's population still lacks access to essential health services, according to a recent monitoring report, ${ }^{1}$ with the disproportionate burden concentrated in low- and middle-income countries. For example, more than 1 billion people live with uncontrolled hypertension, more than $\mathbf{2 0 0}$ million women lack adequate access to family planning, and annually, at least 100 million people fall into poverty because of out-of-pocket health expenses. Even when people can access health services, poor quality of services frequently limits their effectiveness. A recent study in eight countries with high mortality showed that effective service coverage (crude coverage adjusted for quality of care) averaged $28 \%$ for antenatal care, $26 \%$ for family planning and $21 \%$ for sick-child care. ${ }^{2}$ Yet, when effective, primary health care can meet $90 \%$ of people's health needs. ${ }^{3}$

As discussed in a linked Analysis article, achieving universal health coverage requires high-performing, person-centred primary health care. ${ }^{4}$ We emphasize that any effort to achieve universal health coverage and the Sustainable Development Goals will also require a deliberate and focused emphasis on the quality of care that is delivered. We describe attributes of high-quality care and outline ongoing efforts toward measurement and performance improvement.

The recent Ebola pandemic showed the fragility of health systems and exposed a collective unpreparedness in the face of global health threats. A recent framework has identified features of a resilient health system - one that is integrated, adaptive, aware, self-regulating and diverse - and acknowledges our global interdependence: with increased international travel, threats that emerge in one part of the world can rapidly affect people in different countries. ${ }^{5}$ To ensure global health security, we must ensure national, subnational and local security, which,

\section{KEY POINTS}

- Achieving universal health coverage and the Sustainable Development Goal targets requires a robust primary health care system.

- Although health facilities require basic infrastructure, supplies and an available workforce, co-existence of these elements will not guarantee delivery of high-quality care. Clinical effectiveness, comprehensiveness of care and interpersonal quality of care are essential for delivering better clinical outcomes.

- Several global frameworks provide indicators to measure, evaluate, quantify and improve quality of care.

- The solution space for primary health care is broad but main lessons are starting to emerge, and further research is required.

in turn, starts with high-quality care at the community level. Primary health care is vital for prevention, management, treatment and palliation of various acute and chronic conditions. In addition, quality primary health care enhances resilience and constitutes the first line of defense for global health security.

The Institute of Medicine describes quality as the "degree to which health services for individuals and populations increase the likelihood of desired health outcomes," ${ }^{\prime 6}$ and the Organisation for Economic Co-operation and Development Health Care Quality Indicators project describes quality as effectiveness, safety and patient-centredness. ${ }^{7}$ Quality primary health care services are enabled through four core functions or attributes: firstcontact accessibility, coordination, comprehensiveness and continuity. ${ }^{8}$ Delivery of primary health care requires several foundational elements: functional capacities such as infrastructure, financing and governance, essential supplies and equipment, flow of information, and qualified health care providers. ${ }^{9}$ However, the co-existence of these elements does not guarantee the delivery of high-quality care. In many low- and middleincome countries, the results of quality indicators of primary health care systems are disappointing. ${ }^{10}$ For instance, the Service Delivery Indicators initiative in eight countries in Africa (Kenya, Madagascar, Mozambique, Nigeria, Senegal, Tanzania, Togo and Uganda) showed high provider absenteeism (14\%-44\%), as well 
as variable diagnostic accuracy (34\%-72\%) and poor adherence to clinical guidelines (22\%-44\%). ${ }^{10}$ These gaps in quality of care are not restricted to low- and middle-income countries, however; medical errors and suboptimal primary preventive screening occur in many high-income countries. In fact, medical errors result in an estimated 43 million injuries annually, of which $66 \%$ occur in low- and middle-income countries. ${ }^{11}$

Health facilities require an ongoing assessment of their functional capacities (supplies, equipment, information and financial flow, available workforce, organization and management, such as supportive supervision). ${ }^{9}$ After ensuring functional capacities are deployed, the emphasis should shift quickly toward measuring and improving the "quality" of care delivered, including clinical effectiveness, comprehensiveness of care and interpersonal quality of care.

How should we measure the quality of primary health care systems? A global initiative called the Primary Health Care Performance Initiative identified 36 core indicators and 56 tailored, more granular indicators to help countries assess and compare the health and robustness of their primary health care system against those of global peers. ${ }^{9}$ These indicators provide information on access, availability, continuity, comprehensiveness, coordination and person-centredness of primary health care services.

Beyond measurement of system quality, we need evaluation of initiatives to improve. A recent study by the World Bank Group analyzed 22 initiatives to strengthen primary health care, in 12 countries at national and subnational levels. ${ }^{12}$ Eight tenets of high-performing primary health care systems were derived: primary health care as first point of contact for most health care needs; functional multidisciplinary care teams; vertical integration of services; horizontal integration of services; advanced information and communication technology; integrated clinical pathways and functioning dual referral systems; measurement standards and feedback; and certification and accreditation. Fundamental efforts to improve the competence of health care professionals (through pre-service education reforms and in-service training) and redesign of service delivery models are high-return interventions to improve the performance of primary health care systems.

The Primary Health Care Performance Initiative (www. phcperformanceinitiative.org) and the Lancet Global Health Commission on High Quality Health Systems in the SDG [Sustainable Development Goal] Era (www.hqsscommission.org), among other global universal health coverage initiatives, provide evidence-based guidance on strategies to improve quality of care and the performance of primary health care systems. Important next steps are to ensure that all low- and middle-income countries have baseline performance indicators on primary health care systems and quality of care; that investments are made in strengthening functional capacities and service delivery, and in research and routine health information systems; and that the lessons learned and innovation from the public and private sec- tors are shared, to foster innovation and accelerate performance improvement. An ambitious agenda to transform the quality front line of health care services is the key to delivering universal health coverage.

\section{References}

1. Evans T, Kieny M-P. Tracking universal health coverage: first global monitoring report. Geneva: World Health Organization; 2015. Available: http://apps.who.int/ iris/bitstream/10665/174536/1/9789241564977_eng.pdf?ua=1 (accessed 2017 Aug. 15).

2. Leslie $\mathrm{HH}$, Malata $\mathrm{A}$, Ndiaye $\mathrm{Y}$, et al. Effective coverage of primary care services in eight high-mortality countries. BMJ Glob Health 2017;2:e000424

3. Rao M, Pilot E. The missing link - the role of primary care in global health. Glob Health Action 2014;7:23693.

4. van Weel $C$, Kidd M. Why strengthening primary health care is essential for achieving universal health coverage. CMAJ 2018;190:E463-6.

5. Kruk ME, Ling EJ, Bitton A, et al. Building resilient health systems: a proposal for a resilience index. BMJ 2017;357:j2323.

6. Institute of Medicine. Medicare: a strategy for quality assurance, Volume 1. Washington (DC): The National Academies Press; 1990. Available: www.nap. edu/catalog/1547/medicare-a-strategy-for-quality-assurance-volume-i (accessed 2018 Jan. 20)

7. Carinci F, Van Gool K, Mainz J, et al.; OECD Health Care Quality Indicators Expert Group. Towards actionable international comparisons of health system performance: expert revision of the OECD framework and quality indicators. Int J Qual Health Care 2015;27:137-46.

8. Starfield B, Gérvas J, Mangin D. Clinical care and health disparities. Annu Rev Public Health 2012;33:89-106

9. Veillard J, Cowling K, Bitton A, et al. Better measurement for performance improvement in low- and middle-income countries: the primary health care performance initiative (PHCPI) experience of conceptual framework development and indicator selection. Milbank Q 2017;95:836-83.

10. Service Delivery Indicators [home page]. 2017. Available: www.sdindicators.org/ (accessed 2017 Aug. 16).

11. Jha AK, Larizgoitia I, Audera-Lopez C, et al. The global burden of unsafe medical care: analytic modelling of observational studies. BMJ Qual Saf 2013;22:809-15.

12. World Bank Group; World Health Organization; Ministry of Finance, P.R.C.; National Health and Family Planning Commission, P.R.C.; Ministry of Human Resources and Social Security, P.R.C. Deepening health reform in China: building high-quality and value-based service delivery. Washington (DC): World Bank; 2016. Available: https://openknowledge.worldbank.org/handle/10986/24720 (accessed 2018 Feb. 21).

Competing interests: Sagar Dugani reports personal fees from The World Bank Group, outside the submitted work.

This article was solicited and has not been peer reviewed.

Affiliations: Division of Hospital Internal Medicine (Dugani), Mayo Clinic, Rochester, Minn.; Nutrition and Population Global Practice (Veillard, Evans), The World Bank Group, Wash.; Institute of Health Policy (Veillard), Management and Evaluation, Dalla Lana School of Public Health, University of Toronto, Toronto, Ont.

Contributors: All authors contributed to the conception and design of the work, drafted the manuscript, revised it critically for important intellectual content, gave final approval of the version to be published and agreed to be accountable for all aspects of the work.

Disclaimer: Sagar Dugani is a member of the CMAJ Editorial Advisory board, and was not involved in the editorial decision-making process for this article.

Correspondence to: Sagar Dugani, dugani.chandrasagar@mayo.edu 